\title{
A auditoria legal na União Europeia: enquadramento, debate actual e perspectivas futuras
}

\author{
José Joaquim Marques de Almeida, Ph D. \\ Prof. Associado convidado da Universidade Aberta - Portugal \\ Prof. Coordenador do Instituto Superior de Contabilidade e Administração de Coimbra - Portugal \\ Economista/Revisor Oficial de Contas
}

\section{RESUMO}

A auditoria legal na União Europeia, encontra-se, presentemente, numa grande encruzilhada. Imposta pelos poderes públicos e pelas directivas comunitárias, é criticada pelos empresários por não acrescentar valor ao negócio, e, duma maneira geral, pela sociedade que ao atribuir-lhe a característica de bem público, esperava dela respostas mais amplas do que aquelas que os auditores, espartilhados por um quadro normativo e jurídico-técnico construído pelas suas associações profissionais, conseguem ou querem facultar ao público em geral. Com efeito, as normas de auditoria que tratam do planeamento, execução e avaliação do trabalho do auditor, têm sido o refúgio eleito pelos auditores e uma justificação esgrimida, unanimemente, pela classe, para recusar liminarmente o alargamento das funções de auditoria à análise da viabilidade da empresa e à detecção de erros e fraudes. Neste contexto, a função de auditoria legal está sendo, na actualidade, fortemente criticada por não proporcionar ao público "certezas" de que: as declarações financeiras estão correctas, a empresa não falirá, não houve fraudes ou irregularidades, a empresa agiu dentro da lei, foi administrada de forma competente e adoptou uma atitude responsável face aos assuntos ambientais e sociais. É, pois, o objectivo deste trabalho, apresentar em relação à União Europeia, a origem da auditoria legal, e, em termos mais gerais, as inquietações do presente e perspectivar a função, num futuro não muito distante.

Palavras-chaves: auditoria legal, diferença de expectativas, expectation gap, trabalho do auditor legal, futuro da profissão, etc..
ABSTRACT

Nowadays, legal auditing in the European Union finds itself facing a great crossroads. Imposed by governments and communitarian guidelines, it is criticized by entrepreneurs for not aggregating value to the business, as well as by society in general which, characterizing legal auditing as a public good, expected it to give more elaborate answers than those which the auditors, closed in by a standardizing and legal-technical framework made up by their professional associations, manage or want to provide to the public in general. Actually, the auditing standards that deal with the planning, execution and evaluation of the auditor's work have been the shelter chosen by the auditors. The auditing profession had unanimously used them as a justification for rejecting the expansion of the functions of auditing to the analysis of the company's viability and the detection of errors and fraud. In this context, nowadays, the function of legal accounting lies under heavy criticism, since it does not provide the public with the "certainties" related to such questions as correct financial statements, the going-concern of the company, the absence of fraud or irregularities, whether the company acted within the law, was administered in a competent way and adopted a responsible attitude with respect to environmental and social issues. The objective of this paper is, then, to present the origin of legal auditing with respect to the European Union and, more generally speaking, to give a picture of the current preoccupations and draw a perspective for the function in relation to the not very distant future.

Keywords: legal auditing, expectation gap, legal auditor's job, future of the profession, etc. 


\section{INTRODUÇÃO}

Nas décadas de 70 e 80, o exercício da actividade profissional da auditoria começou a ser questionada pela sociedade, quer quanto à sua finalidade, quer quanto à sua utilidade pública.

Esta polémica, que envolve ainda hoje a auditoria, alcança uma maior intensidade nos países anglosaxónicos e menos noutros países, precisamente naqueles países possuidores de uma maior experiência no campo da auditoria, para quem a autoregulação profissional implicou um nível superior de exigência social e onde a detecção da fraude tem sido um dos principais objectivos exigidos à auditoria.

Com efeito, a questão da fiabilidade das auditorias e da responsabilidade profissional dos auditores é fruto de sucessão de determinados escândalos financeiros que foram o detonante da contestação cada vez mais profunda, matizada, em termos de área geográfica, com graus de intensidade diferentes.

No entanto, há um conjunto de problemas comuns, que giram em volta daquilo que se convencionou chamar as diferenças de expectativas em auditoria. Ou seja, as diferenças existentes entre a natureza e alcance do trabalho do auditor e aquilo que esperam os utilizadores da auditoria.

A controvérsia está acesa, e as diferentes entidades interessadas na profissão ainda não chegaram a conclusões quanto às modificações e inovações a introduzir na profissão de auditoria, permanecendo, portanto, no escuro, qual o futuro da actividade como serviço público.

Assim, tendo em conta as discussões já geradas noutros países acerca desta problemática (Inglaterra, Estados Unidos, França, Espanha e Portugal), pretendemos posicionar a auditoria no sentido de haver uma maior aproximação entre as expectativas dos profissionais e dos utilizadores.

Na União Europeia, as auditorias têm igualmente sofrido um grande desgaste, apesar de o desenvolvimento da sua prática, em maior escala, datar dos fins dos anos 70. Sendo, no momento, uma actividade legal, com regulamentação muito apertada, bastante jovem, encontra-se, já, numa grande encruzilhada, sendo contestada pelos empresários com o argumento de que não acrescenta valor ao negócio. Esta crítica, na maioria dos países, é acentuada em período de crise, não deixando, contudo, de ser uma opinião rastejante que vai corroendo os alicerces da profissão.

\section{ENQUADRAMENTO E ÂMBITO DA AUDITORIA LEGAL NA UNIÃO EUROPEIA}

\subsection{Enquadramento Geral}

Na UE esta actividade foi prevista pelas $4^{a}$ e $7^{a}$ directivas que dispõem que as contas anuais e as contas consolidadas devem ser auditadas por um profissional devidamente habilitado, em conformidade com a $8^{\underline{a}}$ directiva.

As disposições das directivas tiveram impacto significativo sobre a legislação da maior parte dos países europeus, considerando-se que a revisão legal das contas é o controlo dos documentos contabilísticos emitidos pelas sociedades ou outras entidades com o objectivo de se conformarem às obrigações legais em matérias de publicação de informações financeiras periódicas (contas individuais ou consolidadas, anuais ou intermédias, relatórios de gestão, etc).

Os resultados deste controlo dão lugar à emissão de uma opinião sob a forma de relatório.

Deve notar-se que em certos Estados Membros, o revisor de contas é igualmente encarregado de certos controlos jurídicos. É nomeadamente o caso dos estabelecimentos de crédito e das companhias de seguro, onde eles preenchem um papel cada vez maior em matéria de controlo prudencial.

A revisão legal das contas é uma actividade regulamentada em todos os países da Europa comunitária, onde o seu exercício exige a posse de uma qualificação ou de um título profissional específico e a inscrição num registo, efectuado pelas autoridades públicas ou pelas organizações profissionais do respectivo país. A Alemanha, Bélgica, Dinamarca, Espanha, França, Grécia, Irlanda, Luxemburgo, Holanda, Portugal e Inglaterra prevêem que as listas dos profissionais capacitados para a revisão legal das contas devem ser objecto de medidas de publicidade, tais como publicação no Jornal Oficial, afixação, estabelecimento de um anúncio, etc, conforme está previsto na $8^{\underline{a}}$ directiva.

À excepção da Itália onde o controlo legal é exclusivo de pessoas físicas, em todos os outros países ele é exercido indistintamente por pessoas físicas ou pessoas morais, isto é, sociedades. 
Neste Estado apenas no passado mês de Outubro foi publicado um projecto de decreto de lei que, a ser publicado, possibilitará o exercício da profissão sob a forma de sociedade, projecto este que está em fase de discussão.

A revisão legal das contas è ainda uma actividade principal para a profissão na maior parte dos países europeus. Esta actividade é regulamentada e reservada à profissão em todos eles, à excepção da Suíça.

$A$ actividade conheceu uma taxa de crescimento sustentado do mercado da revisão legal das contas nos últimos anos, devendo decrescer no futuro, embora se espere ainda uma progressão significativa em Espanha, França, Áustria, Noruega e Portugal, tendendo depois para a estabilização.

\subsection{Aspectos específicos}

Por auditoria do sector público deve entender-se a auditoria das entidades de direito público que não obedecem às regras do direito das sociedades e que têm portanto obrigações diferentes em matéria de informação financeira. Os exemplos mais correntes serão a Segurança Social, os hospitais públicos, as autarquias, etc.

Ainda que tradicionalmente o controlo deste sector caiba aos Tribunais de Contas, os profissionais de contabilidade são cada vez mais frequentemente chamados a intervir, em complemento ou em substituição daqueles. O exercício desta actividade, onde ela é permitida, sob a forma de sociedade, obedece às regras previstas para a revisão legal das contas em quase todos os países europeus, salvo a Espanha e a Itália onde esta possibilidade não é admitida.

As condições de formação profissional, as garantias mínimas a apresentar, a deontologia profissional e as condições de estabelecimento profissional, são em tudo idênticas às exigidas para a revisão legal das contas, excepto em Espanha, onde existe uma regulamentação particular desta actividade, em matérias de exame, garantias, deontologia, etc., que é estabelecida pelo Tribunal de Contas. Na Suécia o revisor está ainda submetido ao Código Penal no que respeita ao segredo profissional.

Em todos os países onde esta actividade está regulamentada, salvo na Espanha e Holanda, os profissionais habilitados a exercer a revisão legal das contas são os únicos autorizados a exercer a auditoria do Sector Público, na parte que não está reserva- da às Instituições Públicas, ou seja, aos Tribunais de Contas.

Espera-se no futuro um assinalável crescimento desta actividade para os revisores oficiais de contas.

Na União Europeia, o controlo das fusões e cisões é uma actividade prevista pelas $3^{\mathrm{a}}$ e $6^{\mathrm{a}}$ directivas do direito das sociedades, que dispõem que um perito independente, designado ou acreditado por uma autoridade judiciária ou administrativa, examine os projectos e emita um relatório escrito destinado aos sócios ou accionistas das sociedades envolvidas na operação.

Este relatório deve indicar os métodos utilizados para a determinação da relação de troca, a adequação dos métodos para os valores em espécie, os valores aos quais cada método conduz, bem como a opinião sobre a ponderação de cada método.

O perito deve por fim concluir se, em sua opinião, a razão de troca é ou não pertinente e razoável, conforme os artigos $10^{\circ}$ da $3^{\underline{a}}$ directiva e $8^{\circ}$ da $6^{\underline{a}}$ directiva.

O controlo das fusões e cisões é uma actividade regulamentada em quase todos os países europeus, à excepção da Suécia e da Suíça.

Todos os países que regulamentam esta actividade não exigem a inscrição em registo ou lista profissional. Quando tal é exigido, as listas não são específicas para o exercício desta actividade, salvo em Itália, onde uma lista "ad Hoc" é efectuada pelos tribunais.

Nos países que regulamentam esta actividade, o controlo das fusões/cisões é efectuado exclusivamente pelos profissionais habilitados a efectuar a revisão legal das contas.

Em todos os países objecto de estudo, este controlo constitui uma actividade marginal ou intermediária.

O controlo das entradas em espécie é uma missão cuja atribuição depende do direito das sociedades de cada país, e nomeadamente das regras relativas à constituição de sociedades e ao aumento do seu capital social.

Na União Europeia, esta actividade foi prevista para as sociedades anónimas (alargada em alguns Estados às sociedades de capitais) pela $2^{\underline{a}}$ Directiva do Direito das Sociedades, que dispõe que as entradas de bens que não em numerário sejam objecto de um relatório emitido previamente à constituição da sociedade ou à realização do aumento do capital, por um ou vários peritos independentes da sociedade, designados ou aprovados por uma autoridade administrativa ou judiciária. 
O quadro legal comunitário no qual se desenvolve esta actividade é praticamente o mesmo que o aplicável ao controlo das fusões.

O controlo das entradas em espécie é uma actividade regulamentada em quase todos os países europeus, à excepção da Grécia, da Suécia, da Suíça e, parcialmente, da Irlanda.

Para além das quatro actividades já mencionadas, regulamentadas na esmagadora maioria dos países europeus, há ainda outras ligadas aos profissionais de contabilidade, tais como consultoria, peritagens, fiscalidade, etc., cuja regulamentação, ou não existe ou é muito diferenciada.

\subsection{0 quadro jurídico - técnico e o âmbito da auditoria}

O quadro jurídico que envolve a auditoria nos países da União Europeia, entende-a como um serviço público, regulando apertadamente a actividade, impondo aos seus agentes normas de trabalho, às quais está subjacente a normativa legal.

Esta normativa delimita as funções dos auditores/ revisores, bem como as responsabilidades que devem assumir.

Com efeito, a auditoria financeira assenta nos postulados de Mautz e Sharaf (1961), e na sua configuração legal obedece a três pontos fundamentais:

- A auditoria é concebida numa perspectiva estritamente técnica, consubstanciada num conjunto de procedimentos visando testar as asserções da administração, reflectidas nas demonstrações financeiras, possibilitando, assim, a emissão de uma opinião profissional.

- A auditoria valida as contas anuais confrontando-as com as normas da legislação comercial, estatutárias e princípios contabilísticos.

- A auditoria baseia-se em documentos processados segundo o modelo contabilístico do custo histórico/moeda nominal, consequentemente, documentos históricos, verificáveis, processados, tratados e agregados por uma determinada entidade.

A concretização destes três escopos fundamentais implica a utilização de técnicas e procedimentos baseados em comprovações parciais, a adopção de técnicas de amostragem que permitem a validação de controles internos administrativos, contabilísticos e informáticos, a verificação exaustiva de determina- dos ciclos de transacções e a avaliação de diferentes áreas de risco.

Obtidas as evidências externas e internas, a actividade de auditoria consiste, tradicionalmente, em emitir uma opinião profissional sobre as contas anuais, de acordo com a regulamentação legal subjacente.

Todavia, as técnicas supracitadas não garantem que $\mathrm{o}$ auditor disponha de toda a informação materialmente relevante. No entanto, o planeamento da auditoria deve ser desenhado no sentido de abranger, de forma ampla, todos os dados relevantes que possam influir no parecer final do auditor.

Esta auditoria assume-se como uma actividade lógica, estrutura-se de forma atomística e reducionista e numa filosofia, cuja fundamentação teórica data de 1961, estruturada por Mautz e Sharaf, tendo subjacente uma economia incrementalista e de produção, e admite que:

- as demonstrações financeiras são verificáveis;

- as demonstrações financeiras e a restante informação sujeita a verificação estão livres de erros intencionais e outras irregularidades anormais; e

- em ausência clara de evidência em contrário, o que se considerou correcto no passado da empresa, sujeita a exame, permanecerá certo no futuro.

A aplicação consistente dos princípios contabilísticos e das normas de auditoria geralmente aceites, impõem, ao auditor, actuando com independência, responsabilidades limitadas ao cumprimento e execução dessas normas.

A análise destes postulados, que representam a âncora técnico-filosófica da profissão, permite-nos desenvolver uma teoria da auditoria financeira, resolver problemas profissionais práticos e esclarecer um conjunto de concepções erróneas sobre a auditoria financeira, sobre os auditores e as suas responsabilidades, gerando, assim, a atenuação das chamadas diferenças de expectativas.

Com efeito, estes postulados fundamentais são e continuam a ser o refúgio dos auditores, ou das concepções mais tradicionais da auditoria, e, decorrentemente, projectam um quadro de responsabilidades muito limitado, que se traduz basicamente no não assumir de responsabilidades pelo descobrimento de irregularidades ou fraudes, e no não comprometimento de diagnosticar a viabilidade futura da empresa, 
exactamente os dois componentes mais relevantes do chamado expectation gap.

Sucede, porém, que, a função social do auditor, o reconhecimento público da profissão, a valorização que a sociedade faz da auditoria, implicaram uma ampliação das obrigações profissionais dos auditores, impondo-Ihes a aceitação de maiores responsabilidades do que aquelas que se encontram estritamente plasmadas nas normas de auditoria geralmente aceites. Esta via, segundo a nossa opinião, é a única que possibilitará a redução do audit expectation gap.

\section{A AUDITORIA LEGAL NA UNIÃO EUROPEIA: O PRESENTE}

\subsection{A problemática do expectation Gap}

O debate actual da auditoria centra-se, portanto, em volta de três problemas fundamentais:

- responsabilidade do auditor;

- alcance real do seu trabalho; e

- utilidade do mesmo.

O reconhecimento atribuído à informação contabilística auditada como tendo a natureza de bem público, e sendo o objectivo precípuo da auditoria a protecção do interesse público, projectam-na para um patamar elevado de responsabilidade social.

Ao assumir um compromisso de auditoria, o auditor aceita executá-la em concordância com certas obrigações estatutárias e leis comuns. O seu não cumprimento implica, potencialmente, litígios com o cliente - entidade com quem o auditor tem relações contratuais - , e com terceiros - entidades com quem o auditor não tem relações contratuais, mas formam grupos interessados na vida económica da empresa e confiam na opinião expressa no relatório do auditor.

Este quadro reflecte o grau de responsabilidade que cada sociedade afecta ao trabalho do auditor, e representa, naturalmente, a valorização que a sociedade faz do seu trabalho, e está, necessariamente, dependente do ordenamento jurídico de cada país. A tradição, em termos mundiais, é profundamente diferente. A tradição jurídica dos países da Common Law favorece a litigância contra os auditores. A reclamação de danos e prejuízos converteu-se num negócio em si mesmo. De tal maneira que o Congresso dos Estados Unidos criticou a expansão das chamadas " indústrias de litígio" em detrimento das indústrias de desenvolvimento.

Contrariamente, nos ordenamentos jurídicos da Roman Law, a teia da responsabilidade do auditor é mais elaborada e complexa, o que explica que o número de litígios, contra os auditores, seja menos significativo.

O segundo problema - o alcance do seu trabalho - é, igualmente, um ponto em profunda análise e discussão. As tendências mais recentes, em sintonia com as preocupações do público em geral, apontam para um maior envolvimento e um papel mais activo na comprovação do princípio da empresa em funcionamento. No fundo, pretende-se que o auditor observe com maior rigor e profundidade o risco inerente do negócio, que são tratados de forma deficiente e displicente no modelo actual de risco, em que os riscos de detecção e controle são mais profundamente meditados do que os riscos do negócio. Impõe-se, por isso, em economia global, a análise de outro tipo de variáveis, tais como:

política financeira, comércio nacional e internacional, avanços tecnológicos, políticas das encomendas nacionais e internacionais, ameaças e oportunidades, estratégia e cadeia de valor. Em suma, uma análise em profundidade da envolvente dos negócios, o que permitirá, com esta informação adicional, melhorar, em grande amplitude, a eficácia social do trabalho de auditoria.

A utilidade do trabalho do auditor é, igualmente, objecto de controvérsia. O entendimento de que a função social do trabalho do auditor não deve limitar-se à simples comprovação e verificação dos registos contabilísticos, é, cada vez, mais partilhada pela comunidade empresarial. A avaliação externa da eficiência e da eficácia da organização, isto é, a análise estratégica da empresa, é reclamada pelas correntes mais abrangentes da auditoria, ao proporem o desenvolvimento do trabalho de auditoria à compreensão da análise da situação estratégica em que se encontra a empresa (Vinten, 1991).

\subsection{Debate sobre a problemática da auditoria legal}

Formulamos oito questões que configuram a problemática actual da auditoria legal. Identificamos duas posições. A posição evolucionista é bastante mais flexível nas respostas, mais adaptada à envolvente so- 
cial, enquanto que a posição clássica é mais conservadora, defensiva e fechada em relação às novas exigências sociais solicitadas à profissão. Contudo, as respostas coincidem em relação à investigação e comunicação de fraudes, sendo divergentes ou quase divergentes nas restantes. Vejamos, o seguinte quadro:

\subsection{Medidas a adoptar para reduzir as expectativas}

As modificações e inovações a introduzir na profissão de auditoria para lhe emprestar uma maior eficácia social, devem ter, por pano de fundo, a sua adaptação à envolvente actual dos negócios e às solicitações pre-

\begin{tabular}{|c|c|c|}
\hline & \multicolumn{2}{|c|}{ POSIÇÕES ACTUAIS } \\
\hline & EVOLUCIONISTA & CLÁSSICA \\
\hline $\begin{array}{l}\text { 1. Há desajustamento entre o serviço de auditoria } \\
\text { e o que os utilizadores esperam da mesma }\end{array}$ & $\begin{array}{l}\text { As funções actuais da auditoria de- } \\
\text { vem ser mais abrangentes, porque } \\
\text { a sociedade moderna exige mais dos } \\
\text { auditores. }\end{array}$ & $\begin{array}{l}\text { As funções da auditoria devem per- } \\
\text { manecer como estão. }\end{array}$ \\
\hline $\begin{array}{l}\text { 2. Como proceder para diminuir o gap das expec- } \\
\text { tativas? }\end{array}$ & $\begin{array}{l}\text { Os auditores deveriam aceitar maio- } \\
\text { res responsabilidades no desenvol- } \\
\text { vimento do seu trabalho. }\end{array}$ & $\begin{array}{l}\text { Reforço do relatório de auditoria so- } \\
\text { bre as debilidades do controlo inter- } \\
\text { no e proposta de soluções. }\end{array}$ \\
\hline $\begin{array}{l}\text { 3. Os relatórios de auditoria deveriam abranger o } \\
\text { diagnóstico da viabilidade futura da Empresa, } \\
\text { bem como as suas dificuldades, mais do que } \\
\text { actualmente se exige? }\end{array}$ & $\begin{array}{l}\text { A incerteza dos negócios encontra a } \\
\text { sua máxima expressão na própria so- } \\
\text { brevivência da empresa. Opinar em } \\
\text { qualquer caso e não só por excepção. }\end{array}$ & $\begin{array}{l}\text { Nenhuma atenção deve ser presta- } \\
\text { da, pelo relatório de auditoria, ao di- } \\
\text { agnóstico da viabilidade futura da } \\
\text { empresa. Opinar só por excepção. }\end{array}$ \\
\hline $\begin{array}{l}\text { 4. Deve a auditoria investigar possíveis fraudes } \\
\text { da direcção e dos administradores? }\end{array}$ & $\begin{array}{l}\text { O auditor tem a responsabilidade so- } \\
\text { cial pela detecção e informação da } \\
\text { fraude. }\end{array}$ & $\begin{array}{l}\text { Posição idêntica. Enfatiza, todavia, a } \\
\text { posição incómoda do auditor. }\end{array}$ \\
\hline $\begin{array}{l}\text { 5. Qual o grau de utilidade dos relatórios de audi- } \\
\text { toria, considerando os diferentes utilizadores? }\end{array}$ & $\begin{array}{l}\text { Alargamento do âmbito do relatório } \\
\text { de auditoria. }\end{array}$ & $\begin{array}{l}\text { Os relatórios actuais são suficientes } \\
\text { para prestar a informação a diferen- } \\
\text { tes tipos de utilizadores. }\end{array}$ \\
\hline $\begin{array}{l}\text { 6. Considera-se justificado o gasto administrativo } \\
\text { da auditoria como obrigação legal para a em- } \\
\text { presa que não se cotizou na Bolsa, e Empre- } \\
\text { sas de tamanho médio ainda que superando } \\
\text { os limites estabelecidos? }\end{array}$ & $\begin{array}{l}\text { O custo associado à auditoria será } \\
\text { bem justificado se, conjuntamente, } \\
\text { oferecer outros serviços de } \\
\text { consultoria e conselho. }\end{array}$ & $\begin{array}{l}\text { Não considera o gasto administrati- } \\
\text { vo justificado, a não ser para as em- } \\
\text { presas cotadas na bolsa. }\end{array}$ \\
\hline $\begin{array}{l}\text { 7. A auditoria é positiva para a Empresa ou é mais } \\
\text { uma obrigação legal que devem cumprir? }\end{array}$ & $\begin{array}{l}\text { É positiva, em termos gerais, porque } \\
\text { contribuem para aumentar o grau de } \\
\text { transparência da informação financeira. }\end{array}$ & $\begin{array}{l}\text { As auditorias legais são mais uma } \\
\text { obrigação que as empresas devem } \\
\text { cumprir. }\end{array}$ \\
\hline $\begin{array}{l}\text { 8. A Empresa auditada é objecto de inspecção e } \\
\text { simultaneamente um cliente para o auditor. Esta } \\
\text { dupla face influi nos relatórios de auditoria pro- }\end{array}$ & $\begin{array}{l}\text { Não deveria influir nos relatórios re- } \\
\text { sultantes. }\end{array}$ & $\begin{array}{l}\text { Influi na emissão de relatórios. Os au- } \\
\text { ditores não são tão inflexíveis e in- } \\
\text { transigentes. }\end{array}$ \\
\hline
\end{tabular}

mentes de uma sociedade moderna. Neste espírito, as mudanças a operar não podem ser concebidas exclusivamente numa perspectiva do auditor, nem numa perspectiva do auditado, mas, sim, enquadrando a auditoria como elemento integrante de uma sociedade que contribui para o seu bem estar. Assim, tendo a auditoria subjacente um conceito social, o facto de se ter transformado numa peça fundamental de controlo social e de responsabilização dos indivíduos e das organizações, transformou-a num padrão aferidor de ética, que, conjuntamente com as necessidades sociais, determinam o sentido social e evolutivo da auditoria. 
Nesta concepção, as expectativas dos profissionais e dos utilizadores devem evoluir no sentido de adaptação ao mundo actual dos negócios.

O não desenvolvimento deste grande ajustamento colocará, a profissão, em risco, em termos de futuro.

Paradigmático é o facto de as organizações de auditores mais avançadas já terem compreendido o repto que se coloca na actualidade e terem adoptado medidas no sentido de estreitar o leque de expectativas.

\section{A AUDITORIA LEGAL NA UNIÃO EUROPEIA: O FUTURO}

\subsection{As novas tecnologias: a emergência do paradigma da auditoria contínua}

"O ambiente gestivo e organizacional é, tipicamente, um ambiente contingente, turbulento, mutável, dinâmico, sistémico, aberto, variado, complexo, entrópico e "copernicano" (Oliveira, 1999).

Com efeito, o reporting financeiro numa envolvente económica caracterizado pela incerteza, não deve limitar-se a oferecer informação imposta unicamente pelos quadros jurídicos actuais - Código das Sociedades Comerciais, C. M. V. M., etc. - , devendo, de preferência, alargar o seu âmbito a um conjunto de informação não estritamente financeira, que pode ser preparada por Empresas especializadas, organismos oficiais e informação fornecida pelas próprias Empresas (Ponte, 2000).

A informação de formato electrónico está em crescimento e é uma realidade nos Estados Unidos, Reino Unido, Irlanda, Alemanha, Finlândia, Espanha, etc., situação que motivou o aparecimento dos primeiros trabalhos produzidos pelo AICPA, CICA, IASC e ICAEW.

Todos estes trabalhos têm como denominador comum o facto de utilizarem tecnologia Web, e proporem a integração do relatório de auditoria no business reporting package, isto é , a auditoria das demonstrações financeiras constitui uma parte do reporting, que pode ser enriquecido por todo um conjunto de informação adicional.

Todos os estudos produzidos apresentam como denominador comum o abandono do clássico conceito de periodicidade da informação financeira, substituindo-o por um conceito de reporting contínuo, muito próximo do reporting em tempo real.

Assim, o relatório do século XXI não será anual nem será um relatório, mas um diálogo permanente entre a
Empresa e os utilizadores, com base numa informação continuamente actualizada e utilizando como veículo de comunicação o Website da companhia.

A necessidade de desenvolver um novo conceito de auditoria contínua adaptado ao reporting on line é fruto de a informação ser publicada com uma periodicidade cada vez menor.

Há, todavia, necessidade de harmonizar, em termos internacionais, os conteúdos, os formatos, em relação às Normas Internacionais de Contabilidade e de Auditoria.

A importância crescente da internet nas relações com os accionistas, auditores e outras entidades interessadas no desenvolvimento da empresa, permite uma actualização e distribuição contínua da informação prestada aos accionistas, possibilitando, inclusivamente, a gravação e participação nas Assembleias Gerais, as reuniões do Conselho de Administração e o voto por correio electrónico.

As novas tecnologias visam o tratamento automático da informação, numa perspectiva sistémica, para lá dos espartilhos da digrafia, da expressão monetária e sem se circunscrever aos limites das necessidades de informação de Gestão de uma unidade económica.

A generalização da linguagem digital dos negócios, possibilitará, à comunidade financeira, um novo quadro de preparação, publicação e análise das Demonstrações Financeiras. Daí concluirmos que a auditoria das demonstrações financeiras cederá o passo à auditoria dos sistemas de informação.

\subsection{Alargamento do âmbito da função}

\section{O auditor face aos Comités de auditoria ou Conselhos Consultivos.}

Os comités de auditoria, implantados nos anos 40, nos Estados Unidos, são órgãos criados pelos Conselhos de Administração, constituídos por conselheiros não executivos e por conselheiros independentes, nos quais os Conselhos de Administração delegam a manutenção dos sistemas de controle interno administrativos e contabilísticos eficazes e adequados. Direccionam, pois, a sua actividade para o desenvolvimento de uma correcta gestão da empresa, visando uma maior transparência e controlo público nas grandes organizações empresariais.

Os comités de auditoria são uma consequência 
lógica de um conjunto de fraudes, irregularidades e práticas corruptas que se produziram em Empresas americanas e inglesas, e visam essencialmente:

- enfatizar aspectos específicos da gestão, como sejam o controle interno e a auditoria, que não costumam ser objecto de preocupação e de interesse por parte de muitos administradores;

- supervisionar as funções de auditoria interna e externa, resultando, daí, um reforço considerável da sua importância através da comunicação imediata que têm com o Conselho de Administração; e

- incluir conselheiros independentes no seio dos comités de auditoria, o que permite reforçar a independência da função de auditoria.

Os comités de auditoria são fruto de uma articulação entre a SEC (Securities and_Exchange Commissions) e a Bolsa de Nova York, que, nos anos 40 , propuseram, às empresas cotadas na Bolsa, a constituição, de forma voluntária, dos comités de auditoria, situação, que foi insistentemente repetida nos anos 60 e 70, fixando-se a data de 30 de Junho de 1978 , como data limite para que, todas as empresas cotadas na Bolsa,

criassem os comités de auditoria, constituídos por pessoas independentes. Estes órgãos foram reforçados com o relatório Treadway ( 1978 ), que lhes atribui funções relevantes na luta contra os relatórios financeiros fraudulentos.

Na Europa, o relatório Cadbury (1992), o relatório Hampel (1996), o relatório Olivencia (1998), o relatório Viennot (1999), entre outros, recomendam a necessidade de as Empresas cotadas na bolsa criarem Comités de auditoria.

A composição dos comités, interessa especialmente aos Revisores Oficiais de Contas, pois, podem integrá-los, como vogais e conselheiros independentes, na medida em que as atribuições e obrigações cabem perfeitamente dentro das funções dos ROC'S.

\section{Análises dos relatórios de risco.}

Mudar o enfoque da auditoria tradicionalmente virado para os controles administrativos e contabilísticos, para o risco de negócio, o que desfocalizará o objectivo da auditoria das peças financeiras para a empresa como um todo, situação perfeitamente conforme à estruturação e desenvolvimento de uma auditoria contínua.

\section{Assumir maiores responsabilidades na análise da viabilidade da Empresa.}

A auditoria das contas anuais, tal como hoje é entendida, não tem por finalidade a detecção de problemas que podem afectar a continuidade da gestão empresarial. Com efeito, as empresas para sobreviverem num ambiente de negócio volátil, têm de estar em permanente mudança. Daí , a incerteza e a análise do risco de negócio, serem, cada vez mais, uma componente de auditoria presente e futura. Como a incerteza dos negócios, e a própria aplicação do princípio da continuidade, alcançam a sua máxima expressão na própria sobrevivência da Empresa, os utilizadores reclamam, do auditor, um papel mais activo. Trata-se de um problema muito sensível em auditoria, em que actualmente se opina exclusivamente por excepção, isto é, unicamente quando existem problemas de continuidade.

No entanto, os últimos relatórios da União Europeia (1996) apontam no sentido de a administração da empresa e o auditor se pronunciarem sobre o futuro mais provável de desenvolvimento da empresa, o que pressupõe a emissão de opinião sobre a sua continuidade em qualquer circunstância. Este facto amplia as funções da auditoria que passará, assim, a englobar o diagnóstico da viabilidade futura da empresa.

Em suma, o auditor deverá tomar e assumir um papel mais activo na análise do negócio em termos de futuro, analisando as ameaças e oportunidades subjacentes ao desenvolvimento das empresas.

\section{A auditoria e a investigação de possíveis fraudes dos directores e administradores - a ética em auditoria.}

A auditoria, na sua génese, tinha por objectivo a investigação de erros e fraudes na empresa. Nos tempos mais recentes, o enfoque passou para a verificação da fiabilidade da informação financeira reflectida nas contas anuais.

Trata-se de um conceito de auditoria financeira muito restrito, constituindo, no entanto, a maior parte da auditoria actual. Há, contudo, uma pressão de mudança muito grande, no sentido de reavaliação da sua actividade, dos seus pressupostos, das suas técnicas e procedimentos.

Entretanto, o desenvolvimento das auditorias operacionais e de gestão, demonstra, necessaria- 
mente, uma função mais abrangente da auditoria. A função social da auditoria impõe a construção de uma opinião sobre a qualidade da conduta dos indivíduos e das organizações, aferida num quadro de normas sociais. Ligando-se a auditoria com as bases de conduta de uma sociedade, o seu problema básico é, essencialmente, ético. É a sociedade que determina as normas de conduta nas diferentes organizações, e quais os aspectos da prestação de contas que devem ser submetidos ao exame do auditor. É basicamente a ética do negócio ou a ética pública que o auditor procura verificar.

Assim, enquanto o conceito de auditoria pode permanecer imutável, a sua interpretação operacional está em contínua evolução, dependendo não só da mudança dos valores éticos, mas, também, do julgamento social em relação a aspectos ou problemas de prestação de contas, aos quais o processo de auditoria pode ser aplicado, tendo subjacente a percepção que a sociedade faz do benefício social de uma auditoria. Neste espírito, a ética e as necessidades sociais determinam a evolução da auditoria.

Neste sentido, é fácil determinar, actualmente, qual a função do auditor/revisor ante a existência de informação financeira fraudulenta. Assim, um maior envolvimento do auditor perante a fraude é uma exigência social premente, fortemente arraigada na convicção pública.

\section{A auditoria dos serviços públicos}

É um novo nicho da actividade dos Auditores/ Revisores Oficiais de Contas que começa a adquirir contornos cada vez mais nítidos e já é solicitada por alguns organismos públicos (v. g. Universidades Públicas). É um mercado com perspectivas importantes de desenvolvimento, em que a auditoria da legalidade dará lugar a uma auditoria da eficiência, pelo que é importante que a Ordem congregue especialistas na matéria para dar formação aos Revisores Oficiais de Contas, neste domínio específico da auditoria.

\section{Diluição das fronteiras entre a auditoria interna e auditoria externa.}

O " corte " tradicional entre auditoria financeira e auditoria interna será rapidamente atenuado. Com efeito, o conceito de auditoria numa perspectiva social, corresponde a um exame efectuado por uma pessoa independente, que compara os objectivos a que a organização se propõe atingir com as realizações e relata os resultados. Este conceito faz parte dos mecanismos de controle público e privado da verificação e prestação de contas.

Por isso, a eficiência e a eficácia começam também a cair no âmbito da auditoria financeira e, simultaneamente, assiste-se à redução sistemática dos departamentos de auditoria interna nas grandes unidades empresariais, sendo os auditores substituídos por consultores de negócios.

\subsection{Globalização e implicações na auditoria legal}

\section{A desregulamentação e as implicações na auditoria estatutária.}

A globalização dos negócios fará emergir, em nossa opinião, como único critério de realização de auditorias: o mercado. Com efeito, não será compreensível, para a opinião pública, e sobretudo para a comunidade empresarial da União Europeia, a manutenção da auditoria legal em empresas familiares. Com efeito, na Europa, a auditoria estatutária é exclusivamente uma obrigação legal que as sociedades têm obrigatoriamente de cumprir. Para as empresas cotadas na Bolsa, com um conjunto de accionistas muito distribuído, encontramos uma justificação válida para a auditoria. Nas empresas familiares, a função da auditoria poderia ser substituída por uma função de auditoria interna, com funções de implantação dos sistemas de controle interno e financeiro da entidade.

A maioria das empresas não vê a auditoria como um elemento que acrescente valor ao negócio. Neste contexto, com a liberalização futura dos honorários, é fácil prever que os ROC'S vão ser confrontados com uma grande pressão, sobretudo, nos períodos de maior recessão económica, pelo que, inevitavelmente, a qualidade do trabalho de auditoria pode decrescer, implicando a utilização de pessoal com menos experiência.

A procura de economias de escala gerará tendências oligopolísticas na profissão, e o recurso sistemático ao outsourcing, quer em auditoria externa, quer em auditoria interna. 
Rotação dos auditores / independência / responsabilidades.

A rotação dos auditores pode vir a ser encarada como uma medida de independência. O relatório Cadbury preconiza a rotação dos auditores, situação timidamente preconizada pela LAC de Espanha, e que tem sido afastada e muito criticada por pressupor, de antemão, a não independência dos Revisores Oficiais de Contas.

\section{Formação dos auditores/ formação de equipas multidisciplinares.}

O auditor do século XXI, para sobreviver necessita de uma formação mais abrangente e multidisciplinar, e menos centrada na contabilidade. Com efeito, além de ser um bom técnico deve ser um bom assessor da empresa ao qual compete compreender o negócio, os riscos do negócio e a sua gestão e trabalhar em equipas globais.

\section{CONCLUSÕES}

A auditoria legal nasceu na União Europeia década de 70 , altura em que surgiram as primeiras vozes de contestação, em relação ao seu âmbito e ao trabaIho desenvolvido pelos auditores.

É perspectivada, nos países da União Europeia, numa matriz estritamente técnica enquadrada num conjunto de normas técnico-profissionais, construídas nos anos 70, e que, na nossa perspectiva, não se adequam àquilo que, actualmente, a sociedade espera requerer da auditoria, isto é, uma análise global da empresa.

As questões formuladas em relação à sua validade actual, apontam para a existência de duas correntes em confronto: o enfoque actual, de características marcadamente evolucionistas, que defende o alarga- mento do âmbito e do alcance da auditoria, e uma perspectiva tradicional, arraigada a uma formulação estritamente técnica da profissão, incapaz de compreender que a auditoria, como todas as técnicas, terá de reflectir as necessidades da sociedade, em que pretende legitimar-se.

A auditoria legal, por consequência, necessita de ser reformulada, quer à luz da nova tecnologia da informação, quer à luz dos novos requerimentos que a sociedade suscita à auditoria.

A desfocalização da auditoria das peças financeiras para a empresa como um todo é um passo fundamental na sobrevivência da função do auditor legal, que terá de ser encarado mais numa perspectiva de um assessor do que um "polícia vigilante", em relação ao cumprimento das normas de auditoria e da contabilidade.

É possível detectar três momentos importantes na evolução da auditoria legal. No passado, o auditor viveu o síndroma da exactidão, em virtude de a sua actividade, em plenitude, estar centrada na fiabilidade das demonstrações financeiras. Actualmente, vive o síndroma da mudança, atendendo à acentuação das contingências da envolvente empresarial.

Futuramente, viverá o síndroma da incerteza, devido ao facto de as empresas poderem perder viabilidade muito rapidamente, pelo que a auditoria tenderá a deslocar-se mais para o contexto, do que propriamente para as peças contabilísticas, situação que a nosso ver, fará emergir, para a auditoria, uma componente mais qualitativa do que quantitativa. Assim, a auditoria tenderá a ser cada vez mais global, ou integral, e menos financeira.

É a sociedade, em consequência, que determina as normas de conduta das diferentes organizações, e quais os aspectos da accountability que devem ser submetidas ao exame do auditor legal. É a ética do negócio ou a ética pública que o auditor procura verificar.

REFERÊNCIAS BIBLIOGRÁFICAS

BECK, G. W. (1973), "The role of the auditor in modern society", Accounting and Business Research, Spring.

GUY, D. M. (1988), "The expectation Gap auditing Standards", Journal of accountancy, Vol. 165.

Livro Verde (1996)

MAUTZ, R. K. e SHARAF, H.A. (1993), The philosophy of auditing. New York: A. A.A., $7^{a}$ Edição.

OLIVEIRA, A. (1999), Anatomia e metabolismo do pro- cesso decisório em contexto empresarial. Algumas questões. Universidade de Évora.

PONTE, H. (2000), " De las cuentas anuales a las cuentas digitales. Presente $Y$ futuro del reporting on line". Livro das Jornadas Luso - Espanhola de Gestão científica. Vilamoura - Algarve.

VINTEN, G., (1991) "The Strategic Audit", Managerial auditing journal, Vol 6. n.ㄴ. 